\title{
Research on the Status of Beijing-Tianjin-Hebei Logistics Operating
}

\author{
Chen Xiaochun \\ Business School, Beijing Wuzi University, Beijing, China
}

Email address:

327640307@qq.com, chenxiaochun_77@163.com

\section{To cite this article:}

Chen Xiaochun. Research on the Status of Beijing-Tianjin-Hebei Logistics Operating. American Journal of Theoretical and Applied Statistics. Vol. 5, No. 5, 2016, pp. 297-304. doi: 10.11648/j.ajtas.20160505.18

Received: July 31, 2016; Accepted: August 9, 2016; Published: August 25, 2016

\begin{abstract}
Beijing-Tianjin-Hebei logistics enterprises has taken place a huge change in the service market under the development direction of personalized, diversified for consumer demand. Fierce market competition forces logistics enterprises to expand and improve its service connotation and extension. After many years, Beijing-Tianjin-Hebei logistics enterprises in constantly enlarging service market, has brought opportunities to innovate business pattern and national development of the logistics industry policy by making full use of the Internet, service organization, service product, service market, service mode innovation, has begun to take shape and provided a good foundation for the development of logistics, from the initial provides a single logistics service to socialization, specialization, and then to comprehensive that the whole society of logistics service, Beijing-Tianjin-Hebei logistics enterprises play an important role in the development of the logistics industry.
\end{abstract}

Keywords: Beijing-Tianjin-Hebei, Logistics Enterprises, Number and Scale

\section{Introduction}

Beijing-Tianjin-Hebei is one of the fastest economic growth, the wealthiest and most open area, so it is a very prominent place. Gross domestic product of Beijing-Tianjin-Hebei was growing from 2011 to 2015, according to preliminary accounts, in 2015, gross total of Beijing-Tianjin-Hebei has risen to 69312.9 billon, accounted for $10.2 \%$ of world, resulting in good prospects for develop regional logistics.
According to the statistics data from Beijing Logistics Association, there are more than 40,000 logistics enterprises in Beijing-Tianjin-Hebei. According to the national statistical indicators, General statistics of logistics enterprises above designated size, the income of 10 million come from logistics services and above logistics enterprise. By the end of 2015, the logistics industry with larger development than 2011 form main business scope, size, income, and so on in Beijing-Tianjin-Hebei, as shown in the table 1.

Table 1. The number and the size of Beijing-Tianjin-Hebei in 2011-2015.

\begin{tabular}{llllllllll}
\hline \multirow{2}{*}{ Year } & \multicolumn{2}{l}{ Number of corporate units above Designated Size } & \multicolumn{3}{l}{ Average practitioner(million) } & \multicolumn{3}{l}{ Logistics business income(billion) } \\
\cline { 2 - 9 } & Beijing & Tianjin & Hebei & Beijing & Tianjin & Hebei & Beijing & Tianjin & Hebei \\
\hline 2011 & 1060 & 772 & 953 & 50.60 & 30.36 & 20.24 & 1891.10 & 1248.06 & 624.06 \\
2012 & 1078 & 790 & 969 & 51.90 & 31.10 & 22.40 & 2104.40 & 1388.94 & 694.45 \\
2013 & 1089 & 802 & 996 & 51.00 & 32.20 & 22.56 & 2267.60 & 1496.61 & 748.11 \\
2014 & 1002 & 776 & 930 & 50.80 & 31.80 & 22.10 & 2482.50 & 1489.50 & 744.75 \\
\multirow{2}{*}{2015} & 971 & 761 & 972 & 51.60 & 31.30 & 21.90 & 2635.20 & 1639.23 & 896.61 \\
& 2704 & & & 104.80 & & & 4171.04 & \\
\hline
\end{tabular}

As can be seen from the table 1 , the overall market demands of the logistics industry have slowed down; the overall level of logistics enterprises income has declined. In Beijing, logistics business income continued to improve nearly five years, average growth rate per annum has reach to $1.04 \%$, the growth at a snail's pace from 2014 to 2015 . Tianjin, in recent five years, average growth rate per annum of logistics business income was $1 \%$, Hebei was $0.69 \%$. Hebei, the development speed of enterprise logistics business income has slowed down. During past five years, the average number of the logistics 
industry employees is basically stable; there is not a big change in Beijing-Tianjin-Hebei.

Logistics companies are still mainly concentrated in transportation, warehousing and other traditional industries in the regional, By the end of 2015, above-scale transport industry has up to 1406 , accounted for $52 \%$ of the Beijing-
Tianjin -Hebei; the number of above-scale warehousing industry has risen to 311 , accounted for $11.5 \%$. The proportion of the two have reached to $63.5 \%$, reflecting the main part of logistics industry is still transportation, warehousing and other traditional, as shown in the figure 1.

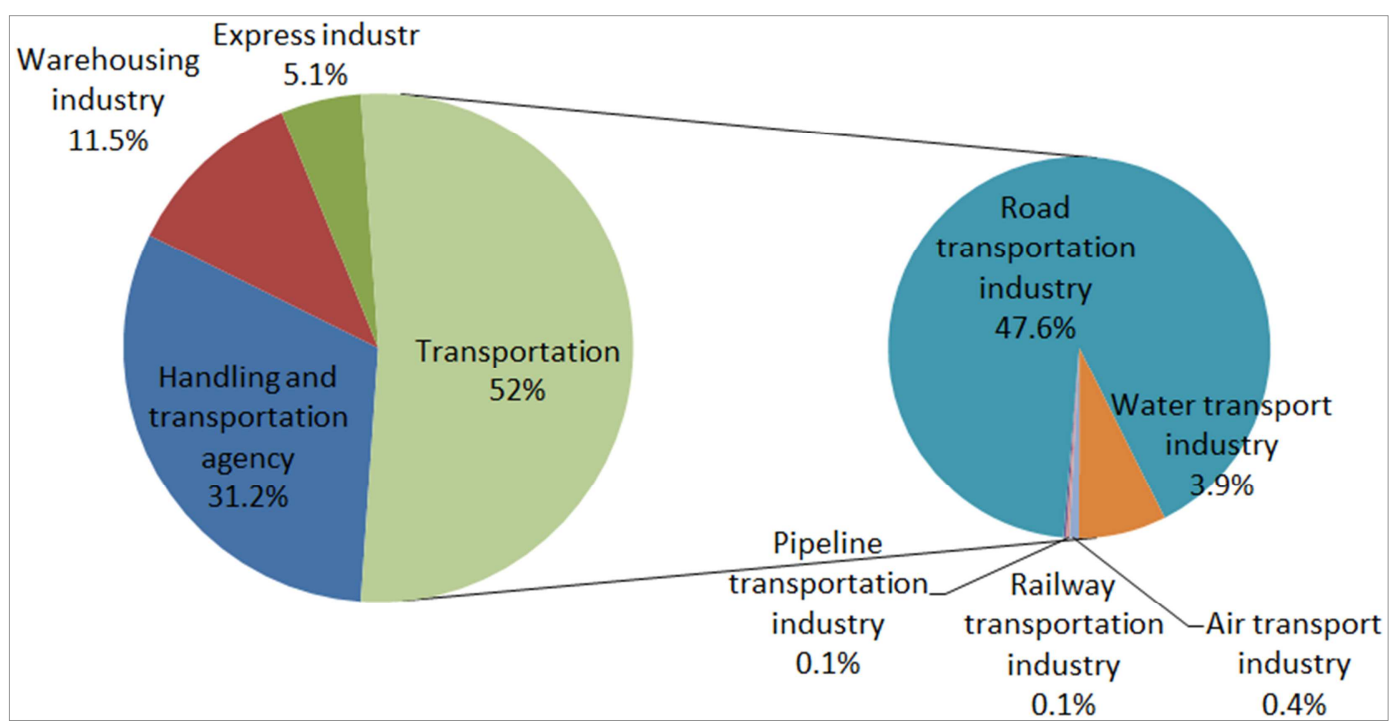

Figure 1. The construction of logistics in Beijing-Tianjin-Hebei.

\section{The Number of Logistics Enterprises in Beijing-Tianjin-Hebei}

\subsection{The Number of Logistics Enterprises in Beijing}

According to the data provided by Beijing Logistics Association, until December 2015, there are more than 8000 logistics enterprises in Beijing; Beijing Statistics Municipal provided the data show, until February 2016, Beijing total number of above-scale enterprises that engaged in transportation, storage and postal express delivery business has reached to 971 . [1]

\subsection{The Number of Logistics Enterprises in Tianjin}

According to relevant statistics, the total number of Tianjin logistics and related enterprises has reached more than 20000, while the larger scale enterprises only a few hundred; Tianjin Statistics Municipal data show, till February 2015, the total number of above scale enterprise that engaged in transportation, warehousing and postal express business in Tianjin has reached to 761. [2]

\subsection{The Number of Logistics Enterprises in Hebei}

According to the Beijing City Logistics Association provided the data, by the end of December 2015, the total number of logistics enterprises in Hebei more than 10000. Hebei Statistics Municipal data show, till February 2015, the total number of above scale enterprise that engaged in transportation, warehousing and postal express business in Hebei has reached to 701. [3]

\section{The Scale of Logistics Enterprises in Beijing-Tianjin-Hebei}

\subsection{The Scale of Logistics Enterprises in Beijing}

Till December 2015, the average number of logistics enterprises employees in Beijing has reached to 51.6 ten thousand. According to the data provided by Beijing Statistical Yearbook, summed up the scale of the logistics industry activities from 2010 to 2014 in Beijing as shown in the table 2:

Table 2. The scale of Beijing logistics in 2010-2014.

\begin{tabular}{lllll}
\hline Year & $\begin{array}{l}\text { Logistics business } \\
\text { income / Billion }\end{array}$ & $\begin{array}{l}\text { Total social } \\
\text { logistics / Billion }\end{array}$ & $\begin{array}{l}\text { Average number of employees in } \\
\text { logistics industry / Million }\end{array}$ & $\begin{array}{l}\text { Transportation, post and telecommunications, the } \\
\text { number of express delivery enterprises / person }\end{array}$ \\
\hline 2010 & 1686.1 & 50424.7 & 48.6 & 1062 \\
2011 & 1891.1 & 59624.5 & 50.6 & 1060 \\
2012 & 2104.4 & 65851.1 & 51.9 & 1078 \\
2013 & 2267.6 & 72440 & 51.0 & 1089 \\
2014 & 2482.5 & 75923.6 & 50.8 & 1002 \\
\hline
\end{tabular}




\subsection{The Scale of Logistics Enterprises in Tianjin}

As of December 2015, the average number of logistics employees in Tianjin has reached to 31.3 ten thousands. According to the Tianjin Municipal Statistical, screening out from 2011 to 2015 in Tianjin, the condition of the logistics industry activities as shown in the table 3.

Table 3. The scale of Beijing logistics in $2010-2015$.

\begin{tabular}{|c|c|c|c|c|c|}
\hline Year & $\begin{array}{l}\text { Increase in transportation, storage, } \\
\text { post and Telecommunications (Billion) }\end{array}$ & $\begin{array}{l}\text { Annual quantity of } \\
\text { shipments (Million Ton) }\end{array}$ & $\begin{array}{l}\text { Annual port capacity } \\
\text { (Billion Ton) }\end{array}$ & $\begin{array}{l}\text { Annual telephone } \\
\text { traffic (Billion yuan) }\end{array}$ & $\begin{array}{l}\text { Express quantity } \\
\text { (Million) }\end{array}$ \\
\hline 2011 & 698.98 & 44651.25 & 4.53 & 180.78 & 5803.03 \\
\hline 2012 & 721.08 & 47697.8 & 4.77 & 186.74 & 7431.99 \\
\hline 2013 & 725.05 & 51602.54 & 5.01 & 220.53 & 9418.5 \\
\hline 2014 & 753.19 & 50947.75 & 5.4 & 243.64 & 12404.23 \\
\hline 2015 & 764.68 & 53179.15 & 5.41 & 321.58 & 25600 \\
\hline
\end{tabular}

\subsection{The Scale of Logistics Enterprises in Hebei}

As of December 2015, the average number of logistics industry employees in the Hebei Province has reached to 21.9 ten thousands. Due to lack of complete data, we only selected part of the logistics data as a reference from 2009 to 2013 , as shown in the table 4 .

Table 4. The scale of Beijing logistics in 2010-2013

\begin{tabular}{llll}
\hline Year & Annual quantity of shipments (Million tons) & Annual port capacity (Ton) & Annual telephone traffic (Billion yuan) \\
\hline 2009 & 136804 & 50874.4 & 1190.7 \\
2010 & 177308 & 60343.8 & 1421.1 \\
2011 & 212330 & 71300 & 537.6 \\
2012 & 242886 & 76234.1 & 572.7 \\
2013 & 277840 & 88984 & 728.7 \\
\hline
\end{tabular}

\section{The State of Operating in Beijing-Tianjin-Heibei Logistics Enterprises}

\subsection{The State of Operating in Beijing Logistics Enterprises}

Beijing national economic and social development statistics bulletin shows that in 2015 the total annual freight volume of Beijing City has reached to 287.652 million tons, down $2.5 \%$ over the previous year. The volume of passenger traffic has reached to 699.231 million. According to the latest data from the Beijing statistics Municipal show that in February 2016, monthly average operating income of logistics that engaged in transportation, warehousing and postal courier business in Beijing has risen 5.1 percent year-on-year. The average number of employees has reached to 586275, rose $-2.0 \%$ percent year-on-year. [4]

There was a significant increase in the logistics business income from 2010 to 2014 in Beijing, especially the indicator of integration logistics business income was exponentially growing. This shows that the ability of providing integrated services logistics enterprises in Beijing has gradually increased. Total social logistics also increased steadily year by year. However, the number of employees is not relatively stable, and even negative growth in 2014. This shows that the development of logistics enterprises in Beijing is not dependent on the increase of human resources, but through the management and technological innovation to achieve revenue growth.

\subsection{The State of Operating in Tianjin Logistics Enterprises}

The main index data of Service Industry from Tianjin Statistics Bureau show that as of February 2015, monthly average operating income of above-scale transportation, warehousing and courier companies in Tianjin has reached to 163.6 billion, monthly average total profit 1.098 billion. According to Tianjin national economic and social development statistics bulletin, in 2015, the annual number of transportation, warehousing and postal services in Tianjin increased to 764.68 billion. There was an increase by $7.7 \%$. Transport logistics enterprises have a steady development. Annual freight volume was 531.7915 million tons. Cargo turnover of 2319.77 billion ton kilometers, among them, the highway has reached to 379.82 billion ton kilometers, up $8.8 \%$; railway 225.79 billion ton kilometers, down $15.0 \%$; water transport 1707.70 billion ton. Tianjin international cruise homeport for the first time to receive 97 cruise ships. [5]

Tianjin logistics indicators are steady growth from 2011 to 2015 , the only growth is the number of express. Express has soared to 256 million in 2015 since 2013. This indicates that there is huge demand for express delivery and a great potential for development exists. 


\subsection{The State of Operating in Hebei Logistics Enterprises}

Annual freight volume is also in the momentum of steady growth in Hebei. Port throughput is also increasing year by year, but the annual throughput of the three major ports in
Hebei province (Qinhuangdao port, Huanghua port, Tangshan port) is still far less than Tianjin. In 2011 postal business volumes have plunged and have began to rise since 2012. The following will show the number and the scale of logistics enterprises in Beijing, Tianjin, as shown in the figure 2.

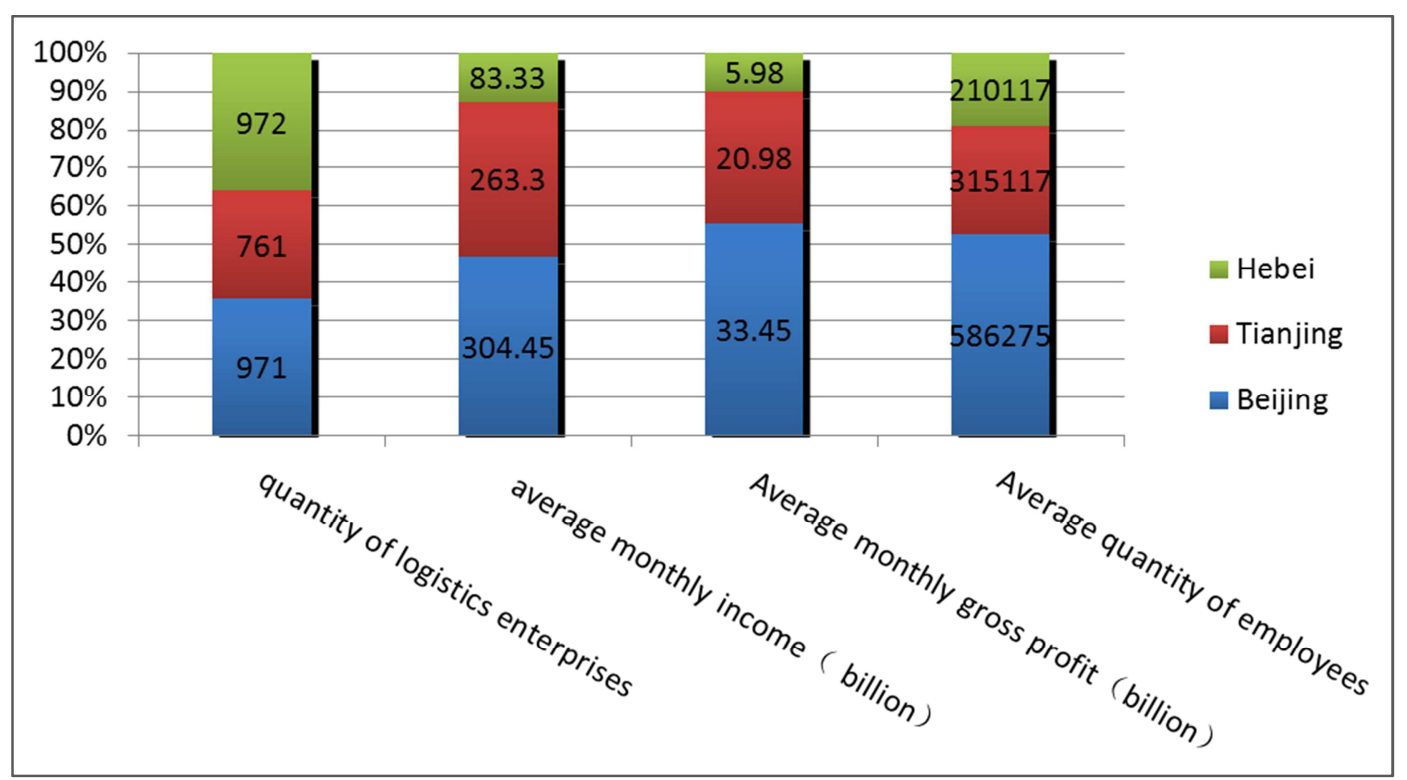

Figure 2. The comparison of the number and scales of logistics in Beijing-Tianjin-Hebei.

It is not difficult to see that the number is basically flat in transport, warehousing and postal courier companies in Tianjin-Beijing-Heibei. However, the area under the jurisdiction of Tianjin and Hebei is much less than Beijing Province, the number of logistics enterprises in Hebei is not significantly more than Beijing and Tianjin, which also reflecting the prosperity of the logistics industry is weak. The average highest income of the company is still Tianjin, followed by Hebei, while the lowest is Beijing, and only accounted for nearly $1 / 4$ of Beijing. [6] It is necessary to improve business ability of Hebei logistics enterprises. Monthly average profit margin in the same income situation of Tianjin-Beijing-Hebei, and Hebei is far from a high profit, which shows that there is a lot of room to improve in profitability in a higher operating cost and lower value-added products. Finally, in terms of the number of employees, Beijing-Tianjin-Hebei has the same situation. Due to the various regions of the Government Statistics website data collection is different, so for, we cannot to do with other representative areas of the country to carry out a specific horizontal comparison.

\subsection{The State of Operating Grade A logistics in Beijing-Tianjin-Hebei}

We can know source from the data that provided by China Federation of logistics and purchasing assessment. The total number of Beijing-Tianjin-Hebei logistics is 167, accounted for $4.6 \%$, the detail data as shown in the table 5 . The condition of grade A logistics in Yangtze River Delta,
Pearl River Delta and Sichuan and Chongqing as following table 6. [7]

Table 5. The number of grade A logistics in Beijing-Tianjin-Hebei.

\begin{tabular}{llllll}
\hline Region & AAAAA & AAAA & AAA & AA & Total \\
\hline Beijing & 27 & 25 & 18 & 3 & 73 \\
Tianjin & 3 & 18 & 11 & 1 & 33 \\
Hebei & 10 & 25 & 23 & 3 & 61 \\
Total & 40 & 68 & 52 & 7 & 167 \\
\hline
\end{tabular}

Table 6. The condition of grade A logistics in Yangtze River Delta, Pearl River Delta and sichuan and Chongqing.

\begin{tabular}{lllllll}
\hline logistics industry & AAAAA & AAAA & AAA & AA & A & Total \\
\hline Yangtze River Delta & 44 & 311 & 489 & 173 & 21 & 1038 \\
$\begin{array}{l}\text { Pearl River Delta } \\
\text { sichuan and }\end{array}$ & 19 & 96 & 78 & 13 & 3 & 209 \\
$\begin{array}{l}\text { chongqing } \\
\text { Total }\end{array}$ & 7 & 27 & 73 & 59 & 0 & 166 \\
\hline
\end{tabular}

The number of Beijing-Tianjin-Hebei logistics enterprises accounted for $4.6 \%$ of the country, the number of the Yangtze River Delta logistics circle logistics enterprises accounted for $28.6 \%$ of the country, the number of the Pearl River Delta logistics circle logistics enterprises accounted for $5.8 \%$ of the country, the number of Grade A in Sichuan and Chongqing logistics enterprises accounted for $4.6 \%$ of the country. To compare the number of the four areas of the grade A logistics enterprise, as shown in the figure 3. 


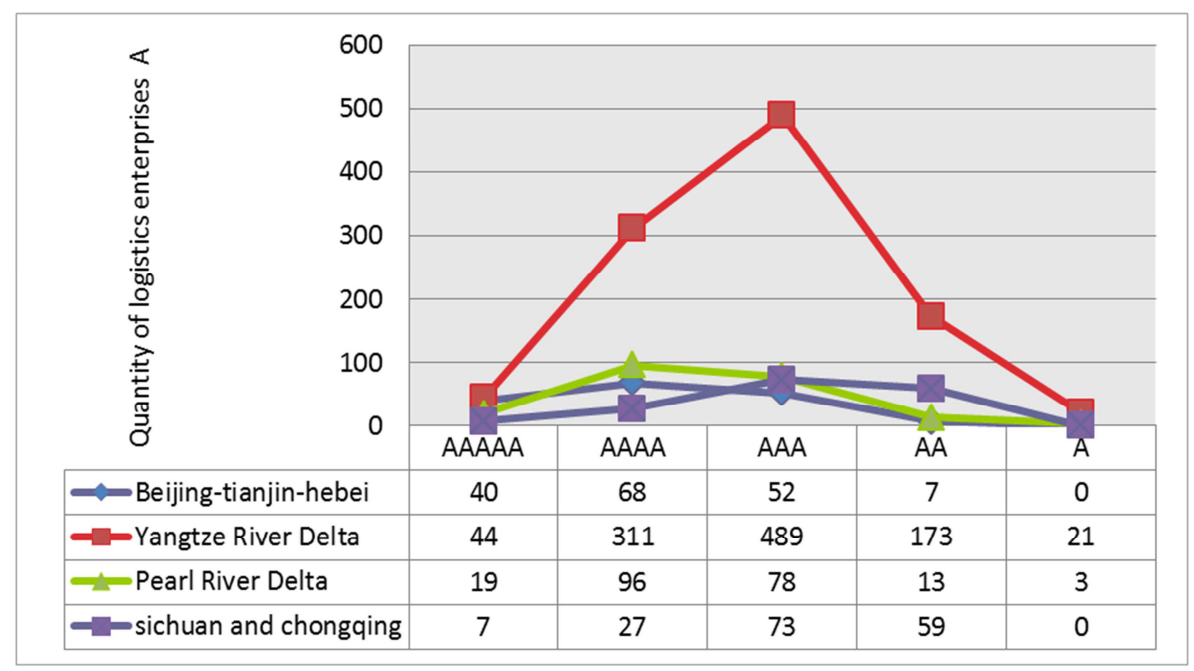

Figure 3. The number of the four areas of the grade A logistics enterprise.

\section{The Basic Operating Conditions of Beijing-Tianjin-Hebei}

In terms of the basic enterprise management situation, we mainly to investigate the enterprise's ownership, main business income, the number of employees enterprise, the type, the main business of enterprises, the scope of business radiation, the number of outlets, city location, set up the average cost of a single dot, and whether or not to participate in the supply chain, and the number and the degree of information sharing.

\subsection{Enterprise Ownership Properties of Beijing-Tianjin-Hebei logistics}

The results of the investigation, as shown in the figure 4, we can find the logistics enterprises involved in the survey in Beijing-Tianjin-Hebei, state-owned enterprises accounted for more than $29.3 \%$, private enterprises accounted for more than $50 \%$ of the wholly foreign-owned enterprises and Sino foreign joint venture or cooperation enterprises accounted for $20.7 \%$.

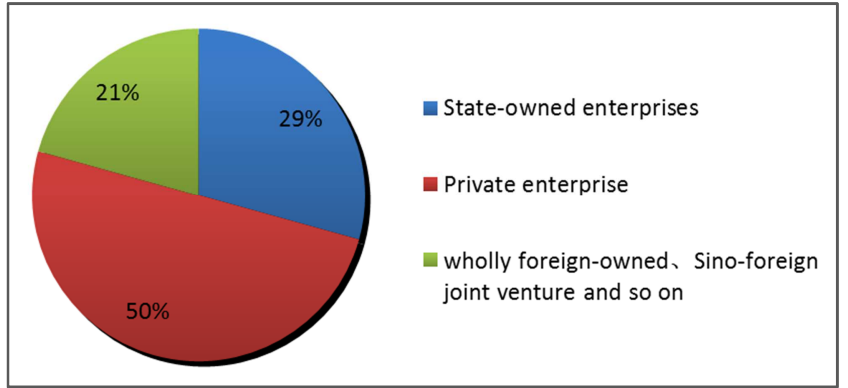

Figure 4. The type of Beijing-Tianjin-Hebei logistics enterprise.

\subsection{The Income Range of Beijing-Tianjin-Hebei Logistics Enterprise}

According to the China information and logistics center, form the survey results of Beijing-Tianjin-Hebei logistics enterprises in 2015, we can take it the main business of the annual income and Beijing-Tianjin-Hebei logistics enterprise income range, as shown in the table 7.

Table 7. The income range of Beijing-Tianjin-Hebei logistics enterprise.

\begin{tabular}{llll}
\hline Annual revenue of main business (Million) & $\mathbf{1 0 0 0} \mathbf{1 0 0 0 0}$ & $\mathbf{1 0 0 0 0} \mathbf{1 0 0 0 0 0}$ & $\mathbf{1 0 0 0 0 0} \mathbf{1 0 0 0 0 0 0}$ \\
\hline Proportion of logistics enterprises & $16 \%$ & $32 \%$ & $36 \%$ \\
Proportion of Beijing City & $18.75 \%$ & $31.25 \%$ & $\mathbf{1 0 0 0 0 0 0}$ \\
Proportion of Tianjin City & $50 \%$ & 0 & $43.75 \%$ \\
Proportion of Hebei City & 0 & $42.86 \%$ & $50.00 \%$ \\
Annual revenue of main business (Million) & $1000 \sim 10000$ & $10000 \sim 100000$ & $14.28 \%$ \\
Proportion of logistics enterprises & $16 \%$ & $32 \%$ & $100000 \sim 1000000$ \\
Proportion of Beijing City & $18.75 \%$ & $31.25 \%$ & $36 \%$ \\
Proportion of Tianjin City & $50 \%$ & 0 & $43.75 \%$ \\
Proportion of Hebei City & 0 & $42.86 \%$ & $50.00 \%$ \\
\hline
\end{tabular}

According to the interval table, the main business income of logistics enterprises in Beijing-Tianjin-Hebei is mainly concentrated between 100 million to 10 billion. The large and medium-sized logistics enterprises accounted for $68 \%$. The income range of logistics enterprises in Beijng is more than 50\% of the total logistics. The overall size of the logistics enterprises is relatively small in Tianjin, the main business income of the logistics business is relatively high in Hebei. [8]

According to the contrast of the level of A logistics companies Beijing-Tianjin-Hebei, the operating conditions of A logistics enterprise in Beijing-Tianjin-Hebei as shown in the table 8 . 
Table 8. The operating condition of grade A logistics in Beijing-Tianjin-Hebei.

\begin{tabular}{llll}
\hline Logistics enterprise grade A & Average number of employees (Person) & Average registered capital (Million) & Average annual income (Million) \\
\hline Logistics enterprise grade 5A & 16853 & 90155 & 1227837 \\
Logistics enterprise grade 4A & 5348 & 26586 & 36316 \\
Logistics enterprise grade 3A & 2900 & 5031 & 18821 \\
Logistics enterprise grade 2A & 1113 & 1233 & 3288 \\
\hline
\end{tabular}

The data information of table 8 derived from the network, because there is not a comprehensive, so we only select the relevant information can be queried and divided by the number of corresponding. So the data of table 8 for reference only.

The scale and operate conditions of logistics business in Beijing-Tianjin-Hebei, as shown in the figure 5.

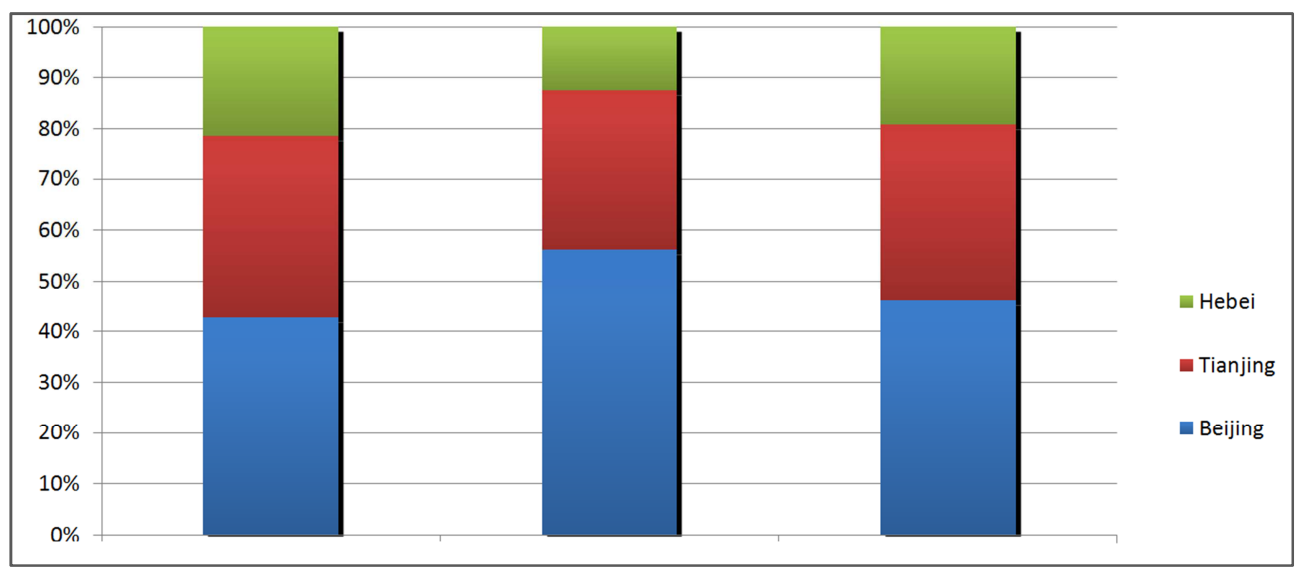

Figure 5. The scale and operate conditions of logistics business in Beijing-Tianjin-Hebei.

According to the scale and the state of A-class logistic enterprise operation in Beijing-Tianjin-Hebei, we can find the condition of the storage and transportation, postal express delivery enterprise are similar. We can also find the logistics enterprises are generally small in Hebei, the average registered capital is lower than the Beijing and Tianjin, and the average annual income is low. All aspects of Hebei province are far behind Tianjin and Beijing, which are worth attention and care.

The collaborative development of Beijing-Tianjin-Hebei should focus on balance; any one aspect of lack or lag will affect or even slow down the overall development pace of
Beijing-Tianjin-Hebei. Now the development of logistics enterprises in Hebei need to get more support and help, whether it is the policy or information technology.

\subsection{The Type and the Main Business Scope of Logistics in Beijing-Tianjin-Hebei}

In terms of the type of logistics enterprises, the questionnaire set up 4 options of transportation, storage, integrated services and other, the results of the survey as shown in the figure 6.

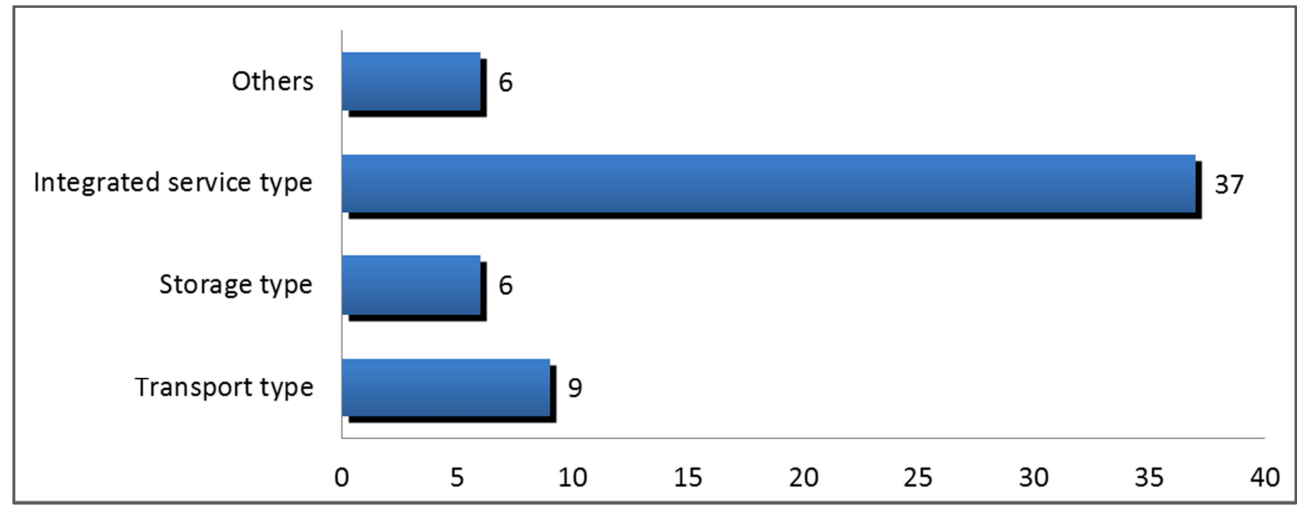

Figure 6. The type of logistics enterprises.

We can see from the figure 6, there are nine logistics enterprises choose the type of transportation, the proportion of $15 \%$; there are six logistics enterprises to choose the type of storage, the proportion is $10 \%$; 37 of logistics enterprises to choose comprehensive service, the proportion of $65 \%$; there are six logistics enterprises to choose the other, accounted for $10 \%$. At present, the majority of logistics enterprises that integrated service in Beijing-Tianjin-Hebei, providing a wider range of logistics services to enhance the competitiveness of logistics enterprises. 
Now third party logistics are more mentioned, due to the different habits of domestic and foreign, and other reasons. The category of the logistics has different standards. Wherein the first third party logistics are now forming, the fourth party logistics in the development stage, as for the fifth party logistics currently parked on the concept and theoretical stage, the fifth party logistics debate and academic study has been in. In this survey, third party enterprises involved in $70 \%$ party logistics enterprises. It is difficult to sort because the concept of confusion. [9]

In the main business of logistics enterprises in Beijing-Tianjin-Hebei, the main business covers of nearly $80 \%$ surveyed enterprises the warehousing, covering the transport and handling of business enterprise scale about $95 \%$, choose distribution business enterprises accounted for more than $80 \%$, and carry out related logistics consultation and logistics system design in the survey accounted for less $40 \%$ in the effective sample. There are 15 logistics enterprises that provide the overall supply chain solutions, accounted for $25.8 \%$. There are 26 logistics enterprises that provide logistics information technology support, accounted for $44.8 \%$.

From point of view of business radiation range in Beijing-Tianjin-Hebei, there are 9 logistics companies in the business scope of Beijing-Tianjin-Hebei and the surrounding areas, the proportion has reached to $15.5 \%$. [10] At the same time, there are 39 investigated in the sample of logistics enterprise business scope covering the country, accounted for $67.2 \%$, which indicated that business scope play an important role in the process of rapid economic growth in Beijing-Tianjin-Hebei. Local logistics enterprises and external contacts continue to strengthen, inter enterprise business tends to be more frequent. In this process, logistics enterprises continue to mature.

\subsection{The Situation of Service Outlets to Establish and Participate in the Supply Chain}

There are many factors need to be taken into account when logistics enterprises plan to expand business, the more prominent factors is the local development policy of logistics, logistics market demand, infrastructure construction and the region supporting logistics service capability, most of the enterprises in the business network location problem is rational. [11] In the survey, there are 30 below the 10 outlets, 10-100 outlets are 12. The average cost of all logistics enterprises in Beijing-Tianjin-Hebei is 2.54 million. This shows that large state-owned enterprises network, low cost to construct, wide coverage of the city, which has a considerable competitive advantage in the area of logistics enterprises. Private and foreign enterprises have shown a disadvantage.

There are $25 \%$ percent in logistics enterprise are involved in supply chain, $70 \%$ of answer questionnaire of Beijing-Tianjin-Hebei logistics enterprises involved in one or more of the supply chain, there are 29 enterprise with under 10 supply chains, more than $80 \%$ of the logistics enterprises information sharing rate has reached to 35 percent. The degree of information sharing has reached to $50 \%-80 \%$. Thus, the majority of logistics enterprises has been involved in the supply chain remove the part for business is not suitable to join, although join the supply chain can improve the level of the logistics enterprise information sharing, there are still a part of space to improve.

\section{Conclusion}

At present, Beijing-Tianjin-Hebei logistics enterprises in the traditional format of small and medium size enterprises, there are small scale, low efficiency, weak competitiveness, and other issues. It is necessary to cultivate large-scale logistics enterprises to support the development of small and medium size logistics enterprises. While supporting the development of small and medium size logistics enterprises by improving the financial logistics services, establishing financial guarantee institutions, supporting the existing transportation, warehouse, freight, courier industry of small and medium size logistics enterprises to prefect function and extension services. It is necessary to actively implement the cooperation of logistics enterprises and finally to achieve inter regional coordinated development. Compared to the logistics market system of the Yangtze River Delta, Pearl River Delta, Beijing-Tianjin-Hebei logistics market is still in the primary stage. So, it is urgent to further increase the construction of enterprise logistics public information platform, so as to improve the ability of logistics service, and promote the transformation and upgrading of logistics enterprises, enhance the core competitiveness of enterprises, which can realize information sharing, network wide linkage, optimize the allocation of social resources, accelerate the formation and healthy development of the modern logistics system.

\section{References}

[1] Statistics website of Beijing [EB/OL]. (2016-03-08) [2016-05-10]. http://www.bjstats.gov.cn.

[2] Statistics website of Tianjin [EB/OL]. [2016-05-10]. http://www.stats-tj.gov.cn.

(2016-03-02)

[3] Statistics website of Hebei [EB/OL]. [2016-05-10]. http://www.hetj.gov.cn.

(2016-03-16)

[4] In 2015, the total GDP nearly 7 trillion accounted for more than $10 \%$ of Beijing-Tianjin-Hebei [EB/OL]. (2016-03-07). http://bj.bendibao.com/news/201637/219257.shtm, Bohai morning post.

[5] Jiao Wenqi. The current situation and problems of Beijing-Tianjin-Hebei logistics enterprise. Economic and trade update. 2008 (05).

[6] Zhu Yanxin, Huang Hongmei, Li Meiyu. An innovative way of logistics collaborative development in Beijing-Tianjin-Hebei (J). Logistics technology, 2015 (11).

[7] Liu Dongying, Cheng $\mathrm{Zi}$. Research on the path and Countermeasure of logistics industry upgrading in Beijing-TianjinHebei (J). Economy and management, 2015 (04).

[8] China Statistical Yearbook in 2015 [EB/OL]. http://www.stats.gov.cn/tjsj/ndsj/2015/indexch.htm 
[9] Analysis on the development of modern logistics industry in China. 2014(04). http://www.chinabaogao.com/.

[10] Shi Jinmei. Development ideas and Counter measures of logistics industry system of Beijing-Tianjin-Hebei $(J)$. China's circulation economy, 2015 (11).
[11] Research and survey data of logistics enterprises in Beijing-Tianjin-Hebei Province from China cold chain logistics alliance.2013. 